\title{
Exercise is a double-edged sword for endothelial function
}

\author{
Yukihito Higashi \\ Hypertension Research (2016) 39, 61-63; doi:10.1038/hr.2015.127; published online 12 November 2015
}

Several lines of evidence have shown that $\checkmark$ aerobic exercise reduces cardiovascular morbidity and mortality in the general population, including hypertension. ${ }^{1,2}$ Although the mechanisms underlying the antiatherogenic and antihypertensive effects of exercise remain unclear, exercise-induced improvement of endothelial function should contribute to reduction in cardiovascular events. Endothelial dysfunction is the initial step in the pathogenesis of atherosclerosis. ${ }^{3}$ Hypertension is also associated with alteration in endothelial function mediated through reduced nitric oxide (NO) bioavailiability. ${ }^{4}$ Exercise is expected to prevent cardiovascular events through an augmentation of endothelial function in patients with hypertension. Indeed, it is well known that aerobic exercise improves endothelial function both in animal models of hypertension and in patients with hypertension., ${ }^{5,6}$ A balance between ambient levels of reactive oxygen species (ROS) and released NO has a critical role in the maintenance of normal endothelial function. A number of mechanisms of improvement in endothelial function during exercise have been postulated. Regular aerobic exercise has beneficial effects on blood pressure, lipid metabolism, glucose metabolism, neurohormonal factors and shear stress. Although the precise mechanism of exercise-induced improvement in endothelial function has not been fully clarified, it has been shown that regular aerobic exercise increases NO production with upregulation of endothelial NO synthase (eNOS) gene expression and

$Y$ Higashi is at Department of Regeneration and Medicine, Research Center for Radiation Genome Medicine, Research Institute for Radiation Biology and Medicine (RIRBM), Hiroshima University, Minami-ku, Hiroshima 734-8551, Japan

Email: yhigashi@hiroshima-u.ac.jp vascular endothelial growth factor-induced angiogeneisis and it decreases NO inactivation with augmentation of activity of components of the antioxidant defense system, such as superoxide dismutase (SOD), glutathione peroxidase and catalase, and attenuation of $\mathrm{NADH} / \mathrm{NADPH}$ oxydase activity, leading to an increase in NO bioavailiability. ${ }^{7}$ These findings suggest that exercise increases NO production and decreases $\mathrm{NO}$ inactivation, leading to an increase in $\mathrm{NO}$ bioavailiability. However, not all types of exercise improve endothelial function. It is clinically important to select the appropriate intensity, duration, frequency and kind of exercise, as highintensity exercise can be hazardous to human vessels. $^{8}$ In general, the guidelines for management of hypertension recommend exercise at an intensity of $\sim 50 \%$ of maximum oxygen consumption, such as walking, jogging, cycling or swimming, for $30 \mathrm{~min}$ per time and 5 to 7 times per week, for patients with mild-to-moderate essential hypertension. ${ }^{9-11}$

Although the mechanisms by which moderate-intensity exercise induces improvement of endothelial function have been investigated in detail, there is little information on the mechanisms by which highintensity exercise impairs or does not alter endothelial function. In this issue, Battault et al. ${ }^{12}$ reported that high-intensity exercise training had no beneficial effects on endothelial function in spontaneous hypertensive rats (SHR). In this animal model of hypertension, high-intensity exercise training induced an increase in oxidative stress, resulting in eNOS uncoupling related to increase in ROS generation and leading to a vicious circle of decrease in NO bioavailiability and increase in ROS. Oxidation of tetrahydrobiopterin $\left(\mathrm{BH}_{4}\right)$ has a critical role in oxidative stress-induced eNOS uncoupling during high-intensity exercise. Under conditions of $\mathrm{BH}_{4}$ deficiency other than oxidation of $\mathrm{BH}_{4}$, eNOS produces ROS, which inactivate NO. ${ }^{13}$ Dysfunctional eNOS with insufficient $\mathrm{BH}_{4}$ causes generation of ROS, resulting in decreased NO activity in prehypertensive SHR. ${ }^{14}$ It has been reported that the degradation of $\mathrm{BH}_{4}$ by $\mathrm{ROS}$, including peroxynitrite, superoxide and hydrogen peroxide, is associated with downregulation of eNOS. ${ }^{15}$ These findings suggest that $\mathrm{BH}_{4}$ deficiency-induced decrease in eNOS activity cause endothelial dysfunction in hypertension through an increase in oxidative stress. There is a possibility that high-intensity exercise activates oxidative stress through exacerbation of $\mathrm{BH}_{4}$ deficiency, as well as oxidation of $\mathrm{BH}_{4}$.

Interestingly, exercise increases not only ROS but also NO in relation to its intensity (Figure 1). An unbalance between $\mathrm{NO}$ and ROS, especially the condition of excess ROS compared with $\mathrm{NO}$, so called 'oxidative stress', under the condition of high-intensity exercise. We cannot deny the possibility that the action of increased ROS that inactivates NO is removed by increased NO production, resulting in maintenance of endothelial function. Moderate-intensity exercise may predominately increase NO production compared with ROS production, leading to augmentation of endothelial function. It is likely that mild-intensity exercise does not alter either $\mathrm{NO}$ or ROS, resulting in no change in endothelial function. Exercise is a double-edged sword for endothelial function.

On the other hand, attention should also be paid to the effects of high-intensity exercise on the antioxidant defense system, too. It is thought that hypertension is associated with diminished activity of the antioxidant defense system. Steady laminar shear stress upregulates the gene expression of 


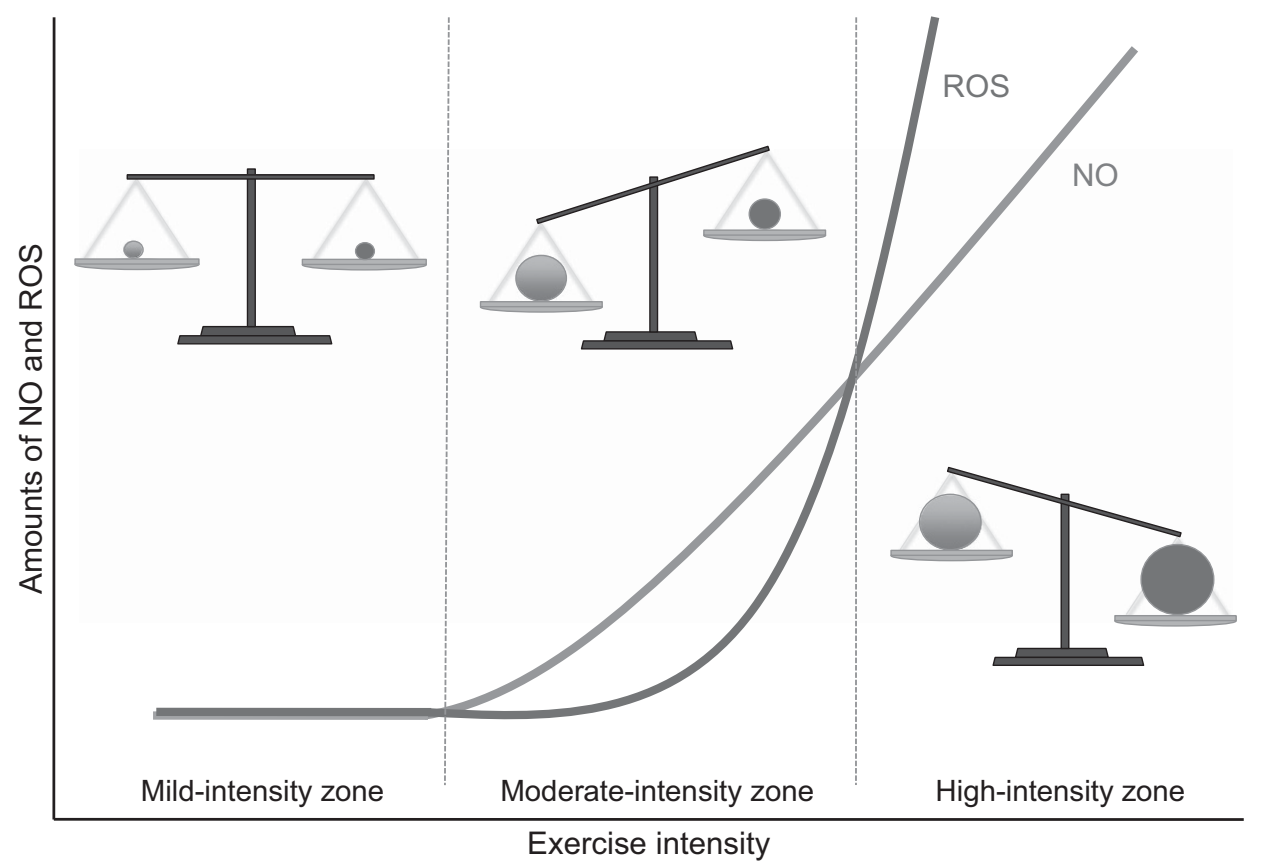

Figure 1 Production of nitric oxide (NO) and reactive oxygen species (ROS) in response to different exercise intensities. During mild-intensity exercise, NO and ROS are constant, resulting in no change in endothelial function. Production of NO and that of ROS are greater during moderate-intensity exercise than during mild-intensity exercise. During moderate-intensity exercise, production of NO is greater than production of ROS, resulting in augmentation of endothelial function. Production of NO and that of ROS are greater during high-intensity exercise than during moderate-intensity exercise. During high-intensity exercise, production of ROS is greater than production of NO, resulting in diminished endothelial function.

$\mathrm{Cu} / \mathrm{Zn} \mathrm{SOD}$ and $\mathrm{Mn}$ SOD in endothelial cells. ${ }^{16}$ Exercise training enhances the protein level and enzymatic activity of SODs, such as $\mathrm{Cu} / \mathrm{Zn} \mathrm{SOD}$ and $\mathrm{Mn} \mathrm{SOD}$, in pig coronary artery endothelial cells. ${ }^{17} \mathrm{~A}$ physiological level of shear stress upregulates glutathione peroxidase mRNA levels and glutathione peroxidase enzymatic activity in cultured bovine aortic endothelial cells. ${ }^{18}$ Adaptive changes in glutathione peroxidase and catalase gene expression in skeletal muscle in response to various types of exercise have been reported. ${ }^{19}$ However, it is not clear whether high-intensity exercise severely impairs the antioxidant defense system or does not alter the system.

We have shown that a 12-week period of exercise of high-intensity increases the indices of oxidative stress, including plasma concentration of 8-hydroxy-2'-deoxyguanosine and serum concentration of malondialdehydemodified low-density lipoprotein, and decreased endothelium-dependent vasodilation in forearm circulation in healthy men. ${ }^{20}$ Davies et al. ${ }^{21}$ reported that the massive increase in oxygen uptake that occurs in skeletal muscle during exercise is associated with an increase in ROS. These findings suggest that high-intensity exercise increases oxidative stress in humans. Therefore, it is thought that increased oxidative stress induced by high-intensity exercise diminishes endothelium-dependent vasodilation in humans. At present, there is no information on the role of high-intensity exercise in the $\mathrm{BH}_{4} / \mathrm{eNOS} / \mathrm{NO}$ pathway in moderation of endothelial function in humans with hypertension. Future studies are needed to evaluate the effects of high-intensity exercise on endothelial function and confirm the precise mechanisms of high-intensity exerciseinduced changes in endothelial function in a general population, including humans with hypertension.

\section{CONFLICT OF INTEREST}

The authors declare no conflict of interest

1 Castelli WP. Epidemiology of coronary heart disease: the Framingham study. Am J Med 1984; 76: 4-12.

2 Paffenbarger RS, Hyde RT, Wing AL, Lee IM, Jung DL, Kampert JB. The association of changes in physicalactivity level and other lifestyle characteristics with mortality among men. N Engl J Med 1993; 328: 538-545.

3 Higashi Y, Noma K, Yoshizumi M, Kihara Y. Oxidative stress and endothelial function in cardiovascular diseases. Circ J 2009; 73: 411-418.

4 Higashi Y, Sasaki S, Nakagawa K, Matsuura H, Oshima T, Chayama K. Endothelial function and oxidative stress in renovascular hypertension. $N$ Engl J Med 2002; 346: 1954-1962.

5 Bernstein RD, Ochoa FY, Xu X, Forfia P, Shen W, Thompson $\mathrm{Cl}$, Hintze TH. Function and production of nitric oxide in the coronary circulation of the conscious dog during exercise. Circ Res 1996; 79: 840-848.
6 Higashi Y, Sasaki S, Yoshimizu A, Ssaki N, Matsuura H, Kajiyama G, Oshima T. Regular aerobic exercise augments endothelium-dependent vascular relaxation in normotensive as well as hypertensive subjects: role of endothelium-derived nitric oxide. Circulation 1999; 100: 1194-1202

7 Hollander J, Fiebig R, Gore M, Bejma J, Ookawara T, Ohno H, Ji LL. Superoxide dismutase gene expression in skeletal muscle: fiber-specific adaptation to endurance training. Am J Physiol 1999; 277: R856-R862.

8 Abraham P, Saumet JL, Chevalier JM. External iliac artery endofibrosis in athletes. Sports Med 1997; 24: 221-226.

9 Guidelines Sub-Committee. 1993 Guideline for the management of mild hypertension: memorandum from World Health Organization/International Society of Hypertension meeting. J Hypertens 1993; 11: 905-911.

10 Chobanian AV, Bakris GL, Black HR, Cushman WC, Green LA, Izzo JL Jr, Jones DW, Materson BJ, Oparil S, Wright JT Jr, Roccella EJ. National Heart, Lung, and Blood Institute Joint National Committee on Prevention, Detection, Evaluation, and Treatment of High Blood Pressure; National High Blood Pressure Education Program Coordinating Committee The Seventh Report of the Joint National Committee on Prevention, Detection, Evaluation, and Treatment of High Blood Pressure: the JNC 7 report. JAMA 2003; 289: 2560-2572.

11 Shimamoto K, Ando K, Fujita T, Hasebe N, Higaki J, Horiuchi M, Imai Y, Imaizumi T, Ishimitsu T, Ito M, Ito $\mathrm{S}$, Itoh $\mathrm{H}$, Iwao $\mathrm{H}$, Kai $\mathrm{H}$, Kario $\mathrm{K}$, Kashihara $\mathrm{N}$, Kawano Y, Kim-Mitsuyama S, Kimura G, Kohara K, Komuro I, Kumagai $H$, Matsuura $H$, Miura K, Morishita R, Naruse M, Node K, Ohya Y, Rakugi H, Saito I, Saitoh S, Shimada K, Shimosawa T, Suzuki H, Tamura K, Tanahashi N, Tsuchihashi T, Uchiyama M, Ueda S, Umemura S. Japanese Society of Hypertension Committee for Guidelines for the Management of Hypertension The Japanese Society of Hypertension Guidelines for the Management of Hypertension (JSH 2014). Hypertens Res 2014; 37: 253-390.

12 Battault S, Singh F, Gayrard S, Zoll J, Reboul C, Meyer G. Endothelial function does not improve with high-intensity continuous exercise training in SHR: 
implications of eNOS uncoupling. Hypertens Res 2016; 39: 70-78.

13 Hinzel $B$, John M, Klatt $P$, Bohem E, Mayer B. $\mathrm{Ca} 2+$ /calmodulin-dependent formation of hydrogen peroxide by brain nitric oxide synthase. Biochem $J$ 1992; 281: 627-630.

14 Cosentino F, Patton S, d'Uscio LV, Werner ER, Werner-Felmater G, Moreau P, Malinski T, Lüscher TF. Tetrahydrobiopterin alters superoxide and nitric oxide in prehypertensive rats. J Clin Invest 1998; 101: 1530-1537.

15 Somers MJ, Falgui BT, Bech-Laursen J, Harrison DG. Interactions between peroxynitrite and tetrahydrobiopterin as a source of altered endothelium-dependent vascular relaxation in atherosclerosis. Circulation 1998; 98: $1-735$.

16 Inoue N, Ramasamy S, Fukai T, Nerem RM, Harrison DG. Shear stress modulates expression of $\mathrm{Cu} / \mathrm{Zn}$ superoxide dismutase in human aortic endothelial cells. Circ Res 1996; 79: 32-37.

17 Rush JW, Laughlin MH, Woodman CR, Price EM. SOD-1 expression in pig coronary arterioles is increased by exercise training. Am J Physiol Heart Circ Physiol 2000; 279: H2O68-H2O76.

18 Takeshita S, Inoue N, Ueyama T, Kawashima S, Yokoyama M. Shear stress enhances glutathione peroxidase expression in endothelial cells. Biochem Biophys Res Commun 2000; 273: 66-71.
19 Ji LL, Fu R, Mitchell EW. Glutathione and antioxidant enzymes in skeletal muscle: effects of fiber type and exercise intensity. J Appl Physiol 1992; 73: 1854-1859.

20 Goto C, Higashi Y, Kimura M, Noma K, Hara K, Nakagawa K, Kawamura M, Chayama K, Yoshizumi M, Nara I. The effect of different intensities of exercise on endothelium-dependent vasodilation in humans: role of endothelium-dependent nitric oxide and oxidative stress. Circulation 2003; 108: 530-535.

21 Davies KJ, Quintanilha AT, Brooks GA, Packer L. Free radicals and tissue damage produced by exercise. Biochem Biophys Res Commun 1982; 107: 1198-1205. 